\title{
Influence of tool offsetting and base metal positioning on the material flow of AA5052-AA6061 dissimilar friction stir welding
}

\author{
L. H. Shah ${ }^{1,2}$, A. R. H. Midawi², S. Walbridge ${ }^{2}$ and A. Gerlich² \\ ${ }^{1}$ Faculty of Mechanical and Automotive Engineering, Universiti Malaysia Pahang, 26600 Pekan, Pahang, Malaysia. \\ Phone: +6094246234; Fax: +609424222 \\ 2 Faculty of Engineering, University of Waterloo, University Avenue West, Waterloo, N2L 3G1 Ontario, Canada
}

\begin{abstract}
This study examines dissimilar friction stir welding of AA5052-AA6061 aluminum alloys with varying tool offsets. The base metals were positioned and fixed at a slight diagonal positioning such that varying tool offset position from the centreline can also be varied along the length of the weld. After the fabrication process, microstructural and mechanical property characterization was subsequently conducted. The results show that, above a certain threshold for tool offset, incomplete consolidation (i.e. kissing bond defects) will occur. Regardless of the base material positioning, a zero tool offset shows optimum intermixing in the stir zone. EDX mapping confirms the presence of a distinct interface between both materials in the stir zone region. However, enhanced material intermixing and better elongation are observed when AA6061 alloy is positioned at the tool advancing side.
\end{abstract}

ARTICLE HISTORY

Revised: 3rd Oct 2019

Accepted: 16 $6^{\text {th }}$ Oct 2019

\section{KEYWORDS}

Friction stir welding;

aluminium alloy;

dissimilar welding;

material flow;

microstructural analysis;

mechanical

characterization.

\section{INTRODUCTION}

Friction stir welding is a welding technique that does not involve melting the material due to its relatively lowtemperature process compared to conventional fusion welding [1]. It utilizes the frictional and deformation heat produced by a rotating tool upon contact with the work piece, which undergoes severe plastic deformation. Once the tool pin is fully plunged inside the work piece, the tool traverses along the faying surface in a linear manner, forming a consolidated joint. Due to its solid-state nature, this technique avoids drastic microstructural changes related to a liquid-to-solid transition, producing a refined structure which can enhance mechanical properties such as tensile strength and fatigue life $[2,3]$.

Recently, numerous studies have been conducted to demonstrate the capability of this welding process in joining dissimilar materials such as between different alloys or between different metals/materials [4-11]. Among others, dissimilar FSW between aluminum alloys is arguably the most widely researched upon, since the majority of FSW applications involves aluminum alloys [12].

Tool offsetting in FSW is a method where the tool centerline is positioned at an offset from the faying surface when traversing through the base materials. It is generally applied in dissimilar welding to obtain optimum material intermixing or to avoid rapid tool wear due to excessive contact with the harder material.

Earlier works utilizing this method involved FSW between aluminum to steel [13, 14], aluminum to magnesium ${ }^{[15-}$ 17], aluminum to copper [18-21] and even aluminum to polymer [22]. Several other works on dissimilar aluminum FSW using tool offsetting technique have also been reported [23-28]. Advantages in tool offsetting includes better fatigue properties [23] and increase tensile strength [28]. These improvements were attributed to enhance intermixing between the alloys.

However, such tool offset setup experiments are usually not cost-efficient, time consuming and has a specific offset fixed prior to the welding process. To solved this issue, Kumar and Kailas [29] demonstrated using AA7020-T6 aluminum alloy that various tool offsetting conditions can be observed if the base material is clamped at a slight angle to the weld line. With this setup, the tool can be positioned so that the pin will plunge in one base material, and after traversing for a given distance, can be retracted out from the other base material. Cross-sectioning the weld joint at various intervals will reveal the instantaneous tool offset at that position, and reveal the stir zone material flow there.

Khan et al. [26] further expanded such setup to investigate its effects on the formation of tunneling and kissing bond defects on 4.75 mm-thick AA5083-AA6063 friction stir welds. They observed that the defects occurred in all offset values toward AA5083 which was positioned in the advancing side (AS), i.e. the side where the velocity vectors of the rotation and traverse direction are similar. They concluded that this is because of insufficient mixing between both alloys.

Thick-plate $5 \times \times \times$ and $6 \times \times \times$ friction stir welds show enormous potential in structural applications [2, 30, 31]. However, information is scarce regarding thick-plate dissimilar $5 \times \times \times$ to $6 \times \times \times$ FSW, particularly pertaining tool offsetting and material positioning. Material flow and intermixing of such thick plates would differ significantly compared to the previous works where the thickness of the plates are reported to be $\leq 6 \mathrm{~mm}$. Under this premise, the current study attempts 
to investigate the effect of tool offsetting and base material positioning on the microstructural and mechanical properties of thick-plate 5052-6061 dissimilar weld joint.

\section{METHODS AND MATERIALS}

The base metals used in this study are aluminum alloy AA5052-H32 (4.7 wt.\% Mg, 0.8 wt.\% Mn) and AA6061T6511 (0.81 wt.\% Mg, 0.53 wt.\% Si) with $9.5 \mathrm{~mm}$ thickness. These base metals were welded using a JAFO horizontal universal milling machine in a butt joint configuration. FSW process was conducted using a H13 tool with $9.3 \mathrm{~mm}$ pin length and $15 \mathrm{~mm}$ shoulder diameter. The pin is fabricated with an $8^{\circ}$ tapered profile and $6 \mathrm{~mm}$ pin root diameter, which was threaded and includes three flats. Figure 1 shows the tool used at different angles. Welding parameters such as tool tilt angle, rotational speed and weld speed was kept constant at $2.5^{\circ}, 1120 \mathrm{rpm}$ and $90 \mathrm{~mm} / \mathrm{min}$, respectively.

As depicted in Figure 2, five cross-sectional samples with locally different tool offsets were cut for metallurgical analysis. The samples underwent standard grinding, polishing and etching procedure to observe the material flow evolution. Samples were etched with Keller's reagent $\left(190 \mathrm{ml} \mathrm{H}_{2} \mathrm{O}, 5 \mathrm{ml} \mathrm{HNO} 3,3 \mathrm{ml} \mathrm{HCl}\right.$ and $2 \mathrm{ml} \mathrm{HF}$ ) for approximately $120 \mathrm{~s}$. Elemental mapping of the sample surface was observed using UltraPlus Field Emission Scanning Electron Microscopy (FESEM).

For mechanical characterization, specimens were cut into ASTM-E8 standard [32] dog-bone shaped coupons and underwent uniaxial quasi-static tensile testing with a crosshead speed of $2 \mathrm{~mm} / \mathrm{min}$. Vickers hardness maps of the samples' cross-section were obtained using a $0.2 \mathrm{kgf}$ load and $10 \mathrm{~s}$ dwell time with $0.5 \mathrm{~mm}$ intervals. To examine the local strain during uniaxial tensile loading, Digital Image Correlation (DIC) technique were also conducted on a $2 \mathrm{~mm}$ thick sample using 29 subsets and a step size of 7. Prior to tensile loading, fine dark speckles were sprayed onto a white layer on the sample in order to observe the local strains. The sample property is assumed to be homogeneous throughout its $2 \mathrm{~mm}$ thickness.
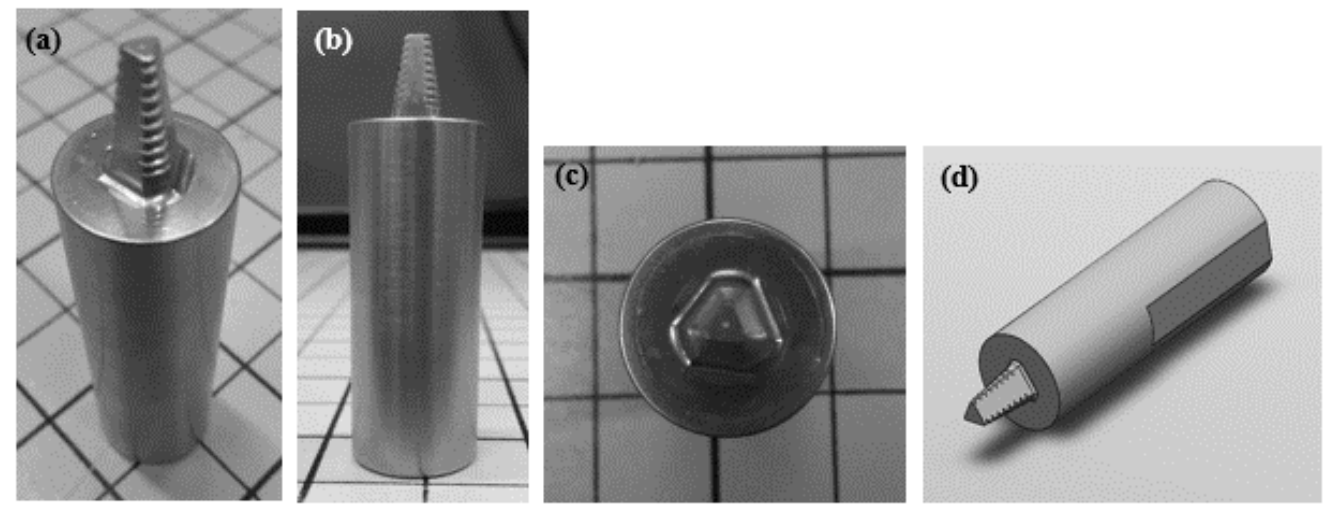

Figure 1. FSW tool with a $15 \mathrm{~mm}$ diameter used in the present study; (a) isometric view, (b) side view, (c) top view and (d) schematic view.

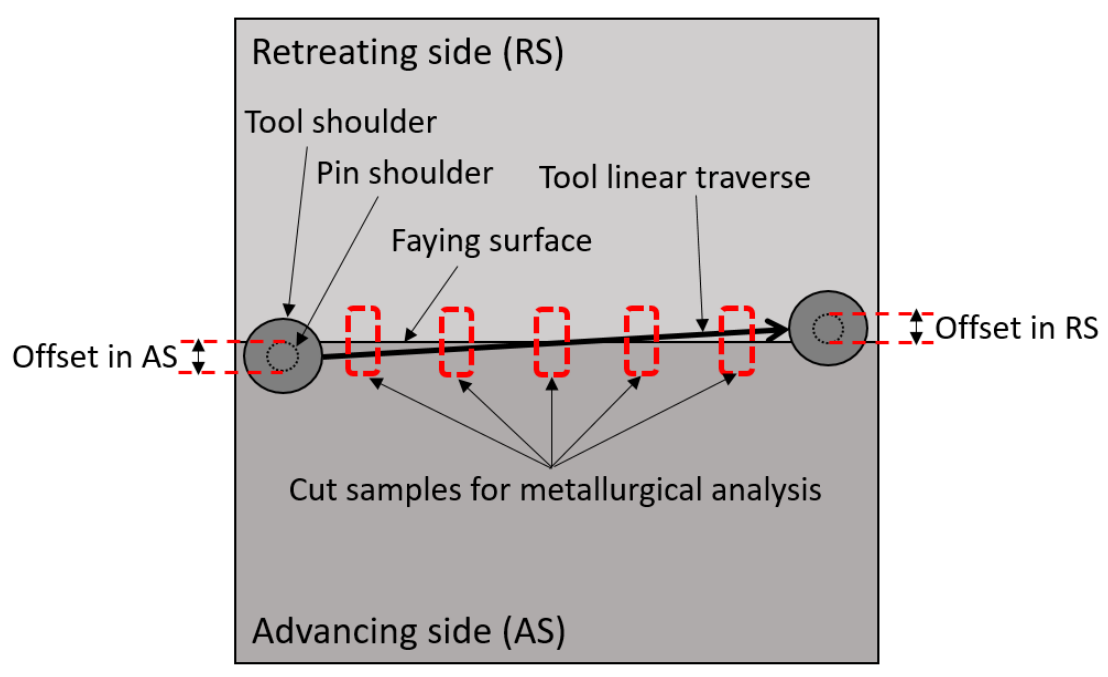

Figure 2. Schematic top view of the FSW process and the relative positions of the cross-sectional samples taken for metallurgical analysis. 


\section{RESULTS}

\section{Microstructural Characterization}

Figure 3 and Figure 4 depicts the cross-sectional samples of 5052-6061 and 6061-5052, respectively, with varying tool offsets. Due to the different reaction of the alloys towards the etchant, good contrast can be observed between both alloys. The red arrows indicate the interface boundary between both alloys. In both figures, the top white arrow represents the centre of the tool pin, while the bottom white arrow depicts the location of the original faying surface between the alloys. In addition, the varying tool offset distance measured from the faying surface is presented at the bottom of each image, where a negative or a positive value denotes that the tool is positioned in the AS material or RS material, respectively. As such, Figure 3(c) and Figure 4(c) shows the material flow condition where the tool pin is approximately at the same position as the faying surface, i.e. zero tool offset.
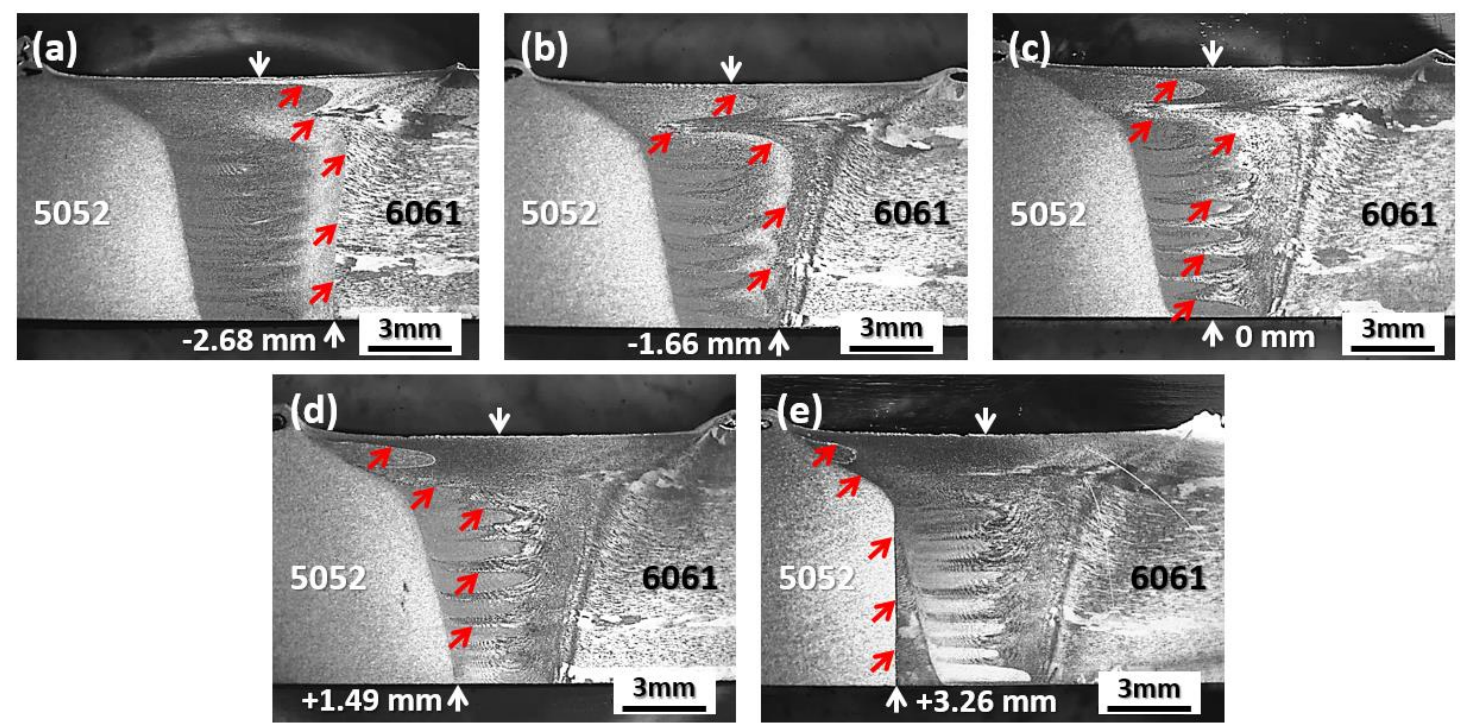

Figure 3. Stir zone material flow evolution of 5052-6061 with varying tool offset. Advancing side is to the left for all images.
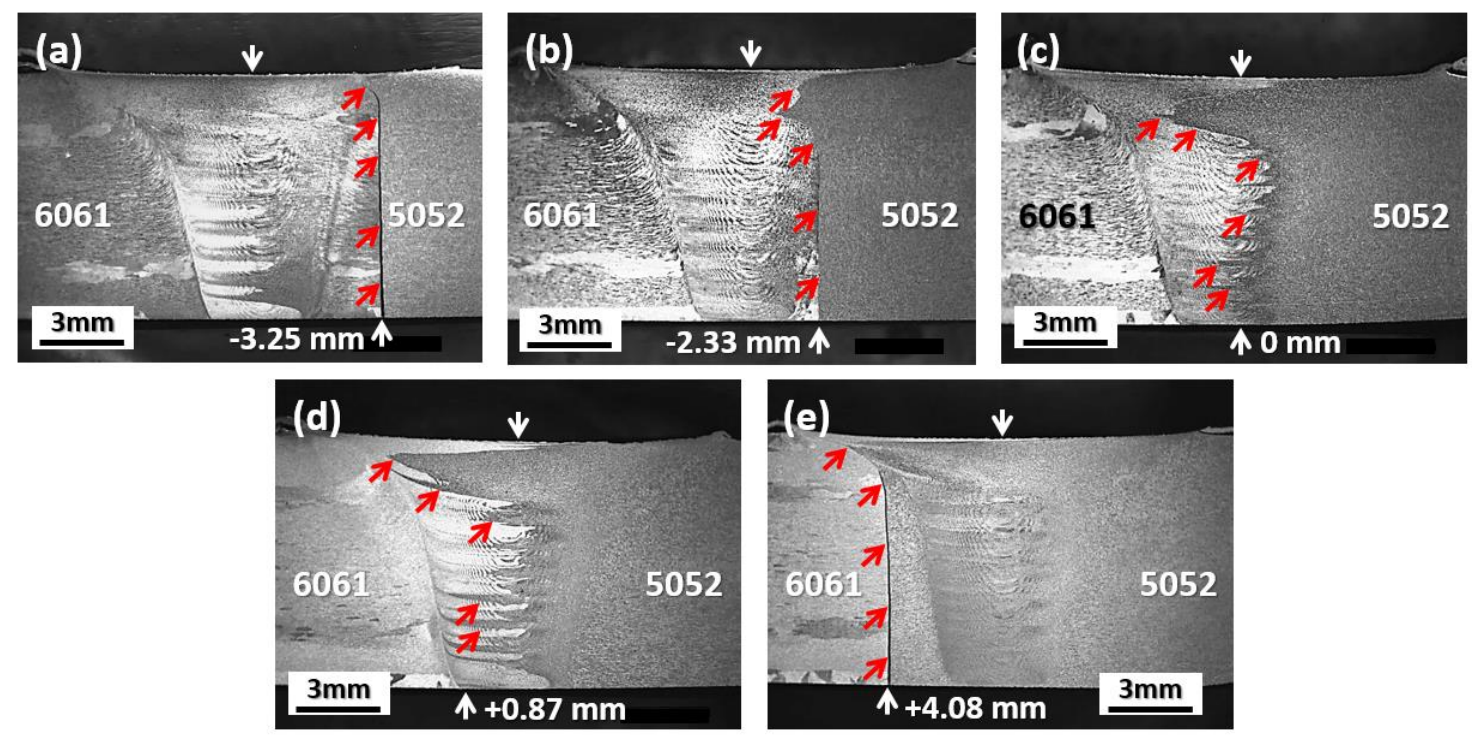

Figure 4. Stir zone material flow evolution of 6061-5052 with varying tool offset. Advancing side is to the left for all images.

In both cases, at a certain tool offset distance, it is observed that incomplete consolidation will from, as shown in Figure 3(e), Figure 4(a) and 4(e). The tool offset values seem to indicate that a value larger than the radius of the pin root $(3 \mathrm{~mm})$ will result in a kissing bond defect and can be a good estimation of the offset limit. However, it should be noted that a tapered pin profile has been used in this study, therefore a slightly larger stir zone width at the weld root can be expected when a cylindrical pin is used, which may expand the tool offset range. 
Both base material orientations on the advancing vs retreating sides show that approximately zero offset setup results in the optimum material consolidation for this alloy combination, where the area of both materials in the stir zone is relatively balanced. Hence, hereafter, several comparative results of 5052-6061 and 6061-5052 with zero offset setup are examined in further detail.
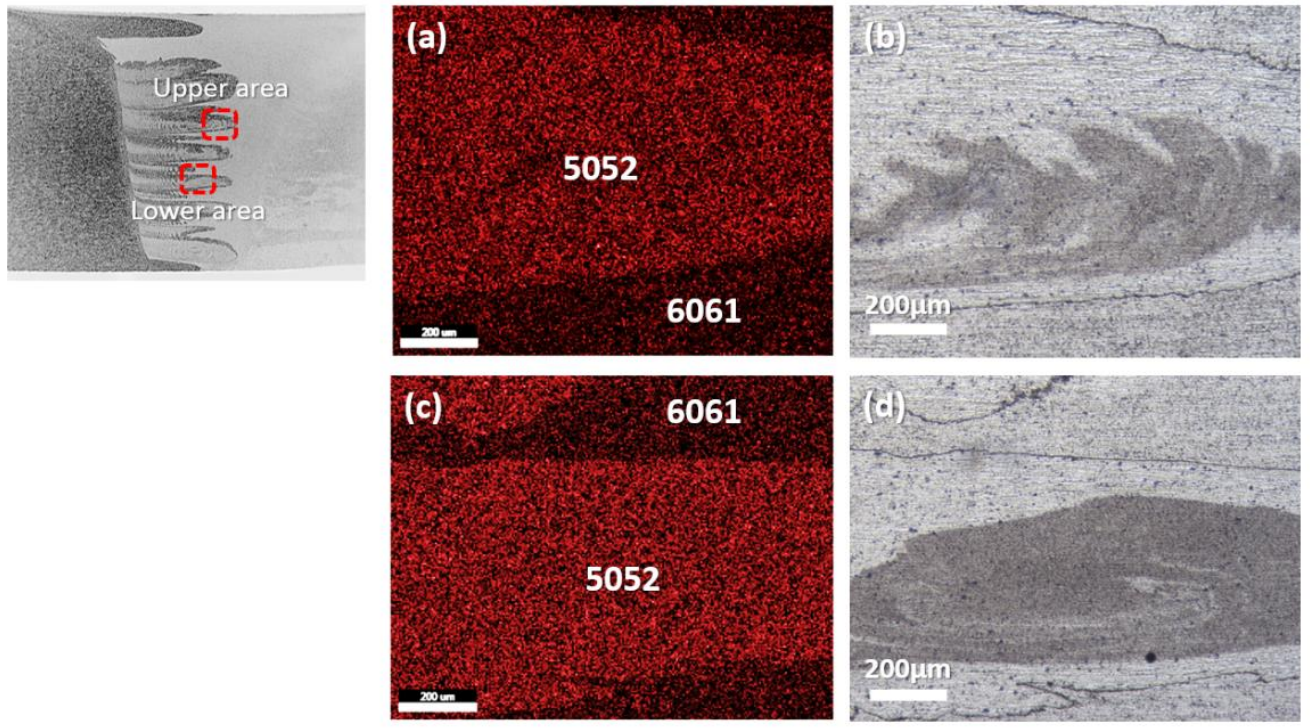

Figure 5. (a) Mg elemental mapping, (b) micrograph of upper area, (c) Mg elemental mapping and (d) micrograph of lower area for 5052-6061 sample.
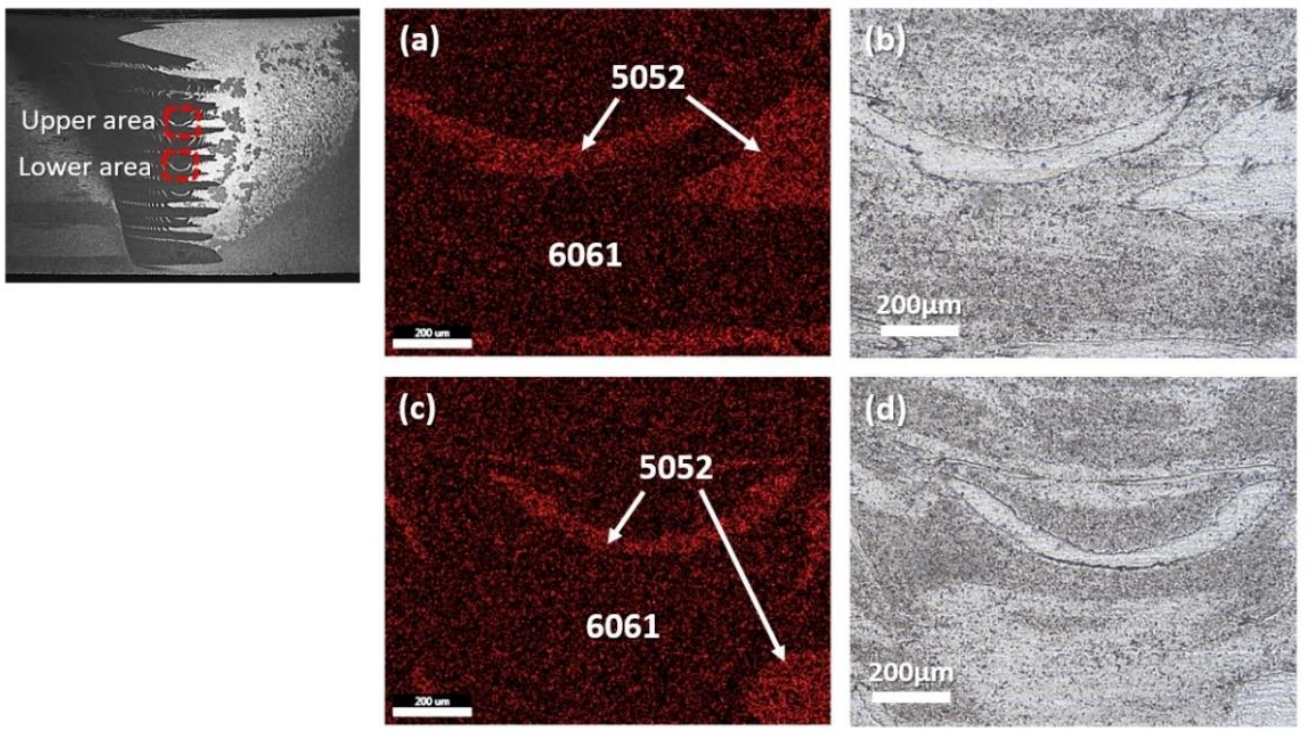

Figure 6. (a) Mg elemental mapping, (b) micrograph of upper area, (c) Mg elemental mapping and (d) micrograph of lower area for 6061-5052 sample.

Where material mixing in the stir zone is concerned, positioning AA6061 in the AS results in better intermixing between both materials. Figure 5 and Figure 6 shows the Mg elemental mapping obtained from EDX for 5052-6061 and 6061-5052 setup with zero offset, respectively. Due to the difference in Mg content (4.7 wt.\% for AA5052 and 0.81 wt.\% for AA6061), a stark contrast can be seen in Figure 5(a) and (b), as well as Figure 6(a) and (b) between the regions dominated by AA5052 (bright region) and AA6061 (dark region). Comparison of the upper area and lower area of 50526061 and 6061-5052 samples clearly demonstrates that better intermixing can be achieved by positioning AA6061 in the advancing side. 


\section{Mechanical Characterization}

Figure 7(a) and 7(b) presents the engineering stress-strain plots for 5052-6061 and 6061-5052, respectively. The purple curves represent the average values taken from three measurements, while the blue and red dashed lines indicate its $90 \%$ confidence levels (90\% CLs). Table 1 tabulates the ultimate tensile strength (UTS) and elongation values for both conditions. Overall, while the UTS is similar, it can be seen that the 6061-5052 joints exhibit greater consistency (based on a narrow $90 \%$ CLs) and a slightly better elongation to fracture, i.e. a tougher material property is achieved.

Regardless of the base metal positioning setup, the final fracture occurred in the heat-affected zone (HAZ) of the AA6061 side, as can be seen in Figure 8. Some degree of necking can be observed at the fracture location, indicative of a ductile failure mode. This is what is typically observed for welded heat-treatable aluminum alloys such as AA6061 where the HAZ is known to be the weakest region due to softening effect and hence would initiate fracture ${ }^{[33-35]}$.

(a)

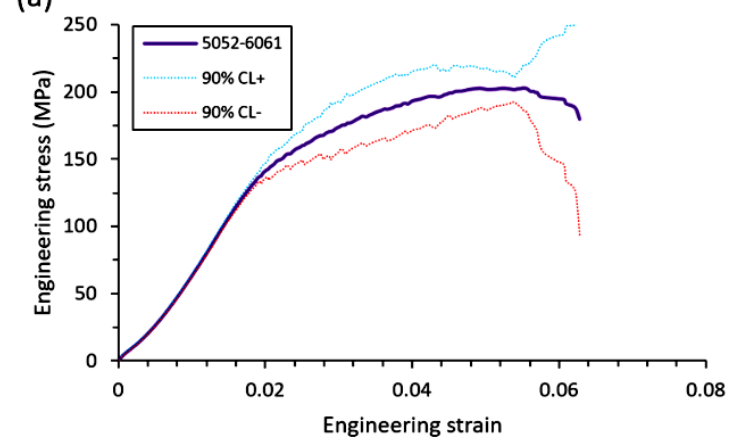

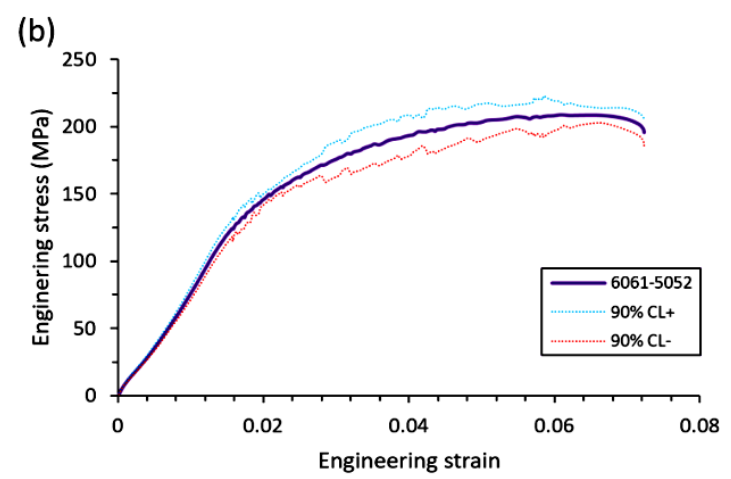

Figure 7. Engineering stress-strain plot for (a) 5052-6061 and (b) 6061-5052 with zero tool offsets. Blue and red dashed lines indicate $90 \%$ confidence levels.

Table 1. Ultimate tensile strength values and elongation to fracture.

\begin{tabular}{ccc}
\hline Sample & Ultimate tensile strength $(\mathrm{MPa})$ & Elongation $(\%)$ \\
\hline $5052-6061$ & $209.7 \pm 1.5$ & $6.5 \pm 0.6$ \\
$6061-5052$ & $209.8 \pm 4.0$ & $7.3 \pm 0.3$ \\
\hline
\end{tabular}

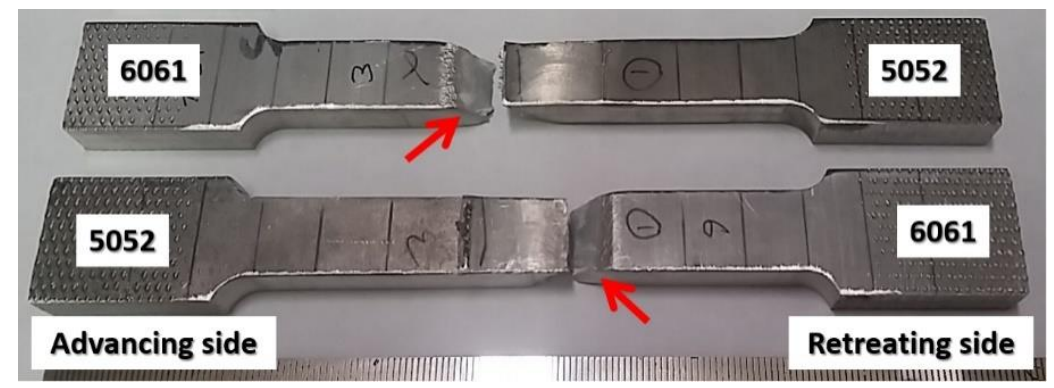

Figure 8. Fractured tensile coupons of 5052-6061 and 6061-5052 with zero tool offset.

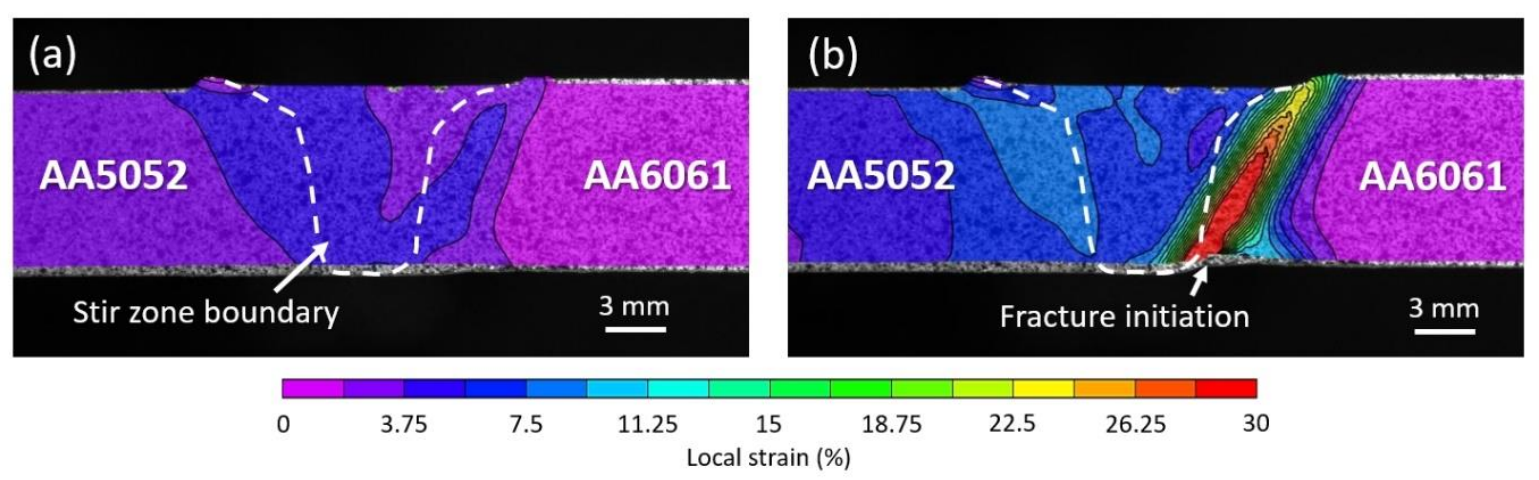

Figure 9. DIC strain map of the 5052-6061 sample (a) during initial straining and (b) right before fracture. Fracture occurred in the HAZ of the AA6061 plate. 

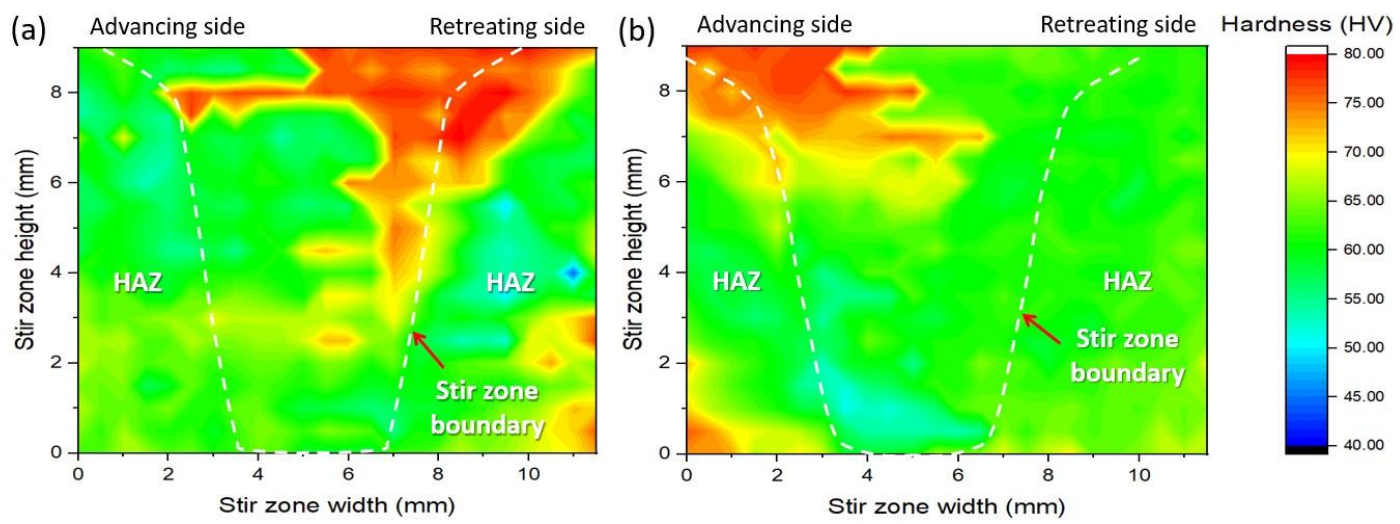

Figure 10. Stir zone and HAZ hardness mapping of (a) 5052-6061 and (b) 6061-5052 specimens.

In addition, Figure 9(a) and 9(b) depicts the DIC image of 5052-6061 sample during the initial straining and final stages of the tensile loading. It was observed that local straining initially formed mainly in the stir zone and HAZ region, but fracture occurred in the HAZ of AA6061 where the local strain measured $>30 \%$.

To further analyze this, the hardness mapping of the stir zone and HAZ for both specimens, as shown in Figure 10. While the stir zone and HAZ region of the AA5052 alloy side in both cases have a rather homogeneous hardness throughout the specimen thickness, a stark hardness gradient in the stir zone region of AA6061 side is observed. Local strains in this location seen in Figure 9 seem to concentrate in the area where the hardness is relatively softer. In addition, softening of the HAZ region is also apparent. Given the hardness inhomogeneity of the through-thickness in the AA6061 side and its softening in the HAZ, it is postulated that these issues facilitated strain localization to concentrate in the HAZ band, leading to final fracture there. Previous work had shown that failure for similar 5052 and 6061 friction stir welds occurred in the stir zone and HAZ, respectively [36]. Figure 9 and 10 suggests that the straining initially occurred throughout the softened stir zone and HAZ of both base metals, but eventually concentrated towards the HAZ of the AA6061 as the tensile testing progresses.

It is also interesting to note that the positioning of the base metal show no effect on the joint strength (Table 1). The minimal change in the straining of the stir zone due to change in the intermixing does enhance the elongation (Figure 7) to a certain degree but would fail at the same stress value since the property of HAZ in 6061 remain the same regardless of positioning and is not affected by changes in stir zone intermixing.

\section{DISCUSSION}

\section{Effect of Tool Offsetting}

During the welding process, the heat generated from the friction between the tool and the workpiece forms a basinlike shearing zone throughout the periphery of the tool-workpiece interface [37]. At the wake of the tool, this shearing zone becomes the stir zone as shown in Figure 3 and 4. The size of the shear zone vary greatly according the material, tool and processing parameters used. Given a particular tool setup, if the faying surface is too far from the tool position, i.e. with a large tool offset, part of the faying surface would not encounter the basin-shaped shearing zone during the translational motion of the tool and would eventually remain as a detrimental kissing bond defect. Minimal or no tool offset would ensure proper shearing of the faying surface which breaks the aluminium oxide layer in order to enhance intermixing.

From the results obtained, it is apparent that welding using no offset gives a balanced volume fraction of both alloys in the stir zone, regardless of the base material positioning. The positioning of the tool with an offset from the faying surface will determine the amount of material from both sides which will be consolidated in the weld mixture. However, it is difficult to estimate by directly calculating the position of the expected stir zone area and areas overlapped by each material. Figure 11 below shows a schematic diagram of AA5052 and AA6061 material volume which will be mixed during FSW [13]. Using this approach, a good estimation can be made regarding the stir zone material mixing. For simplicity, several assumptions are made; (i) the shape of the material volume is assumed to be parallelepiped; (ii) there is no tilt angle; (iii) and the effect of base metals being in advancing side or retreating side is neglected.

Referring to Figure 11, with tool pin diameter $6 \mathrm{~mm}\left(L_{5052}+L_{6061}\right)$ and densities of both alloys are $\rho_{5052}=$ $2.68 \mathrm{~g} / \mathrm{cm}^{3}$ and $\rho_{6061}=2.7 \mathrm{~g} / \mathrm{cm}^{3}$, respectively, the mass of the volume for AA5052 and AA6061 alloy becomes

$$
\begin{aligned}
& W_{5052}=W \times H \times L_{5052} \times \rho_{5052} \\
& W_{6061}=W \times H \times L_{6061} \times \rho_{6061}
\end{aligned}
$$


respectively, where $W$ is width, $H$ is height and $L$ is length for each material. The weight fraction of AA5052 within the stir zone can be calculated as

$$
f_{w t, 5052}=\frac{W_{5052}}{W_{5052}+W_{6061}}
$$

Therefore, substituting Eqs. (1) and (2) into (3) yields:

$$
f_{w t, 5052}=\frac{1}{1+1.01\left(\frac{L_{6061}}{L_{5052}}\right)}
$$

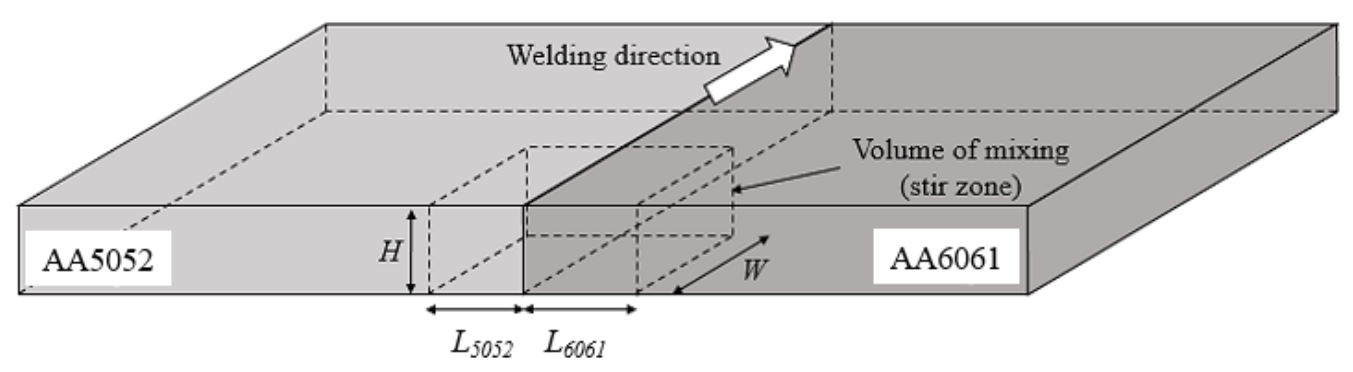

Figure 11. Schematic of material volumes of AA5052 and AA6061 which will be mixed during FSW.

Table 2. Weight fraction of 5052 and 6061 in the weld nugget as a function of tool offset.

\begin{tabular}{cccc}
\hline Weight fraction & $\begin{array}{c}L_{5052}=L_{6061} \\
\text { (No offset) }\end{array}$ & $\begin{array}{c}L_{5052}=4 \mathrm{~mm} \\
L_{6061}=2 \mathrm{~mm}\end{array}$ & $\begin{array}{c}L_{5052}=2 \mathrm{~mm} \\
L_{6061}=4 \mathrm{~mm}\end{array}$ \\
\hline AA5052 & 0.49 & 0.66 & 0.33 \\
AA6061 & 0.51 & 0.34 & 0.67 \\
\hline
\end{tabular}

The possible weight fraction of both metals in the stir zone as a function of tool offset for three arbitrary conditions are shown in Table 2. From the calculations, it can be implied that, given the condition that a balanced weight fraction is desirable, i.e. an equal mixture of both base metals, a zero tool offset setup is ideal, as empirically proven in Figure 3 and Figure 4. Note that, since the density of both alloys is rather similar, the zero offset approach is expected.

Table 3. Weight fraction of $\mathrm{Al}$ and $\mathrm{Mg}$ in the weld nugget as a function of tool offset.

\begin{tabular}{ccccc}
\hline $\begin{array}{c}\text { Dissimilar } \\
\text { FSW }\end{array}$ & $\begin{array}{c}\text { Weight } \\
\text { fraction }\end{array}$ & $\begin{array}{c}L_{A l}=L_{M g \text { or } F e} \\
\text { (No offset) }\end{array}$ & $\begin{array}{c}L_{A l}=4 m m \\
L_{M g \text { or } F e}=2 m m\end{array}$ & $\begin{array}{c}L_{A l}=2 \mathrm{~mm} \\
L_{M g \text { or } \mathrm{Fe}}=4 \mathrm{~mm}\end{array}$ \\
\hline $\mathrm{Al}-\mathrm{Mg}$ & $\mathrm{Al}$ & 0.61 & 0.76 & 0.44 \\
& $\mathrm{Mg}$ & 0.39 & 0.24 & 0.56 \\
\hline $\mathrm{Al}-\mathrm{Fe}$ & $\mathrm{Al}$ & 0.26 & 0.41 & 0.15 \\
& $\mathrm{Fe}$ & 0.74 & 0.59 & 0.85 \\
\hline
\end{tabular}

In comparison, Table 3 shows the possible weight fraction between several base materials in the weld nugget for a given Al-Mg and Al-Fe dissimilar FSW under similar conditions and using the same approach, where the nominal density for Al, $\mathrm{Mg}$ and Fe is $\rho_{A l}=2.7 \mathrm{~g} / \mathrm{cm}^{3}, \rho_{M g}=1.738 \mathrm{~g} / \mathrm{cm}^{3}$ and $\rho_{F e}=7.86 \mathrm{~g} / \mathrm{cm}^{3}$, respectively. Due to the difference in material density, it can be seen that a zero offset approach may not give an ideal material mixing, but slightly offsetting the tool in the material with lower density, i.e. magnesium in the Al-Mg case and aluminum in Al-Fe case, might be a better approach. In addition, applying this would also ensure prolonged tool life since the pin is mainly shearing in the softer material. However, since tool design, welding parameters and material thickness play an equally important role in stir zone intermixing, the method mentioned should only be taken as an initial estimation and does not negate the importance of validation through proper experimentation.

\section{Material Flow and Intermixing}

To maximize the intermixing between base metals in friction stir welding, the rule of thumb is to place the harder base material in the advancing side [38-40]. However, since FSW is a high-temperature process, the change in hardness as temperature increases should be considered. It is generally accepted that $H V=3 \sigma_{U T S}$ [41], where $H V$ is the hardness 
value in Vickers and $\sigma_{U T S}$ is the Ultimate Tensile Strength (UTS). Observing the UTS change as temperature increases (Figure 12) can provide a better understanding regarding base material positioning.

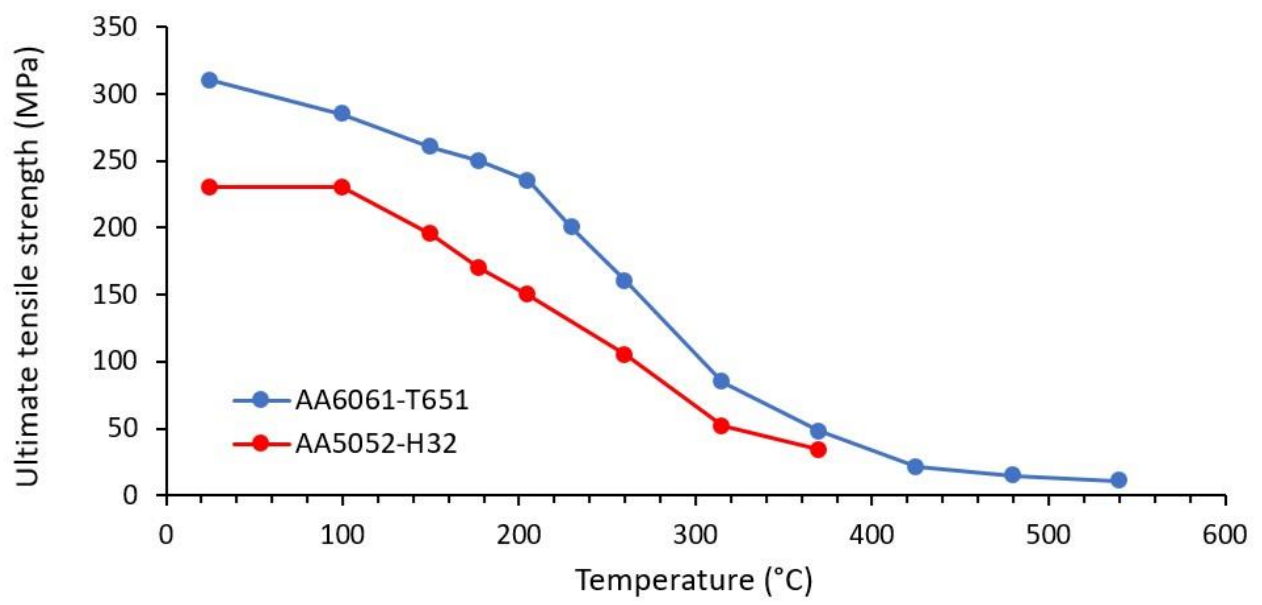

Figure 12. Ultimate tensile strength as a function of temperature for AA6061 and AA5052 [42].

As depicted in Figure 12, at elevated temperatures approaching $400^{\circ} \mathrm{C}$, AA6061 consistently maintains higher UTS (i.e., higher hardness). It is also known that the AS material undergoes higher shearing activity compared to RS material [43]. Therefore, intuitively the harder material should be placed on the AS location so that better intermixing can occur as a result of enhanced shearing of the harder material. The EDX results from this study (Figure 5 and 6) agrees well with this rule of thumb.

\section{CONCLUSIONS}

Dissimilar friction stir welding of AA5052-AA6061 with varying tool offset and base material positioning was successfully conducted. The results are summarized below:

1) Tool offset plays a major role in the stir zone material flow. Incomplete consolidation will occur when a critical offset value is exceeded.

2) In both base material positioning conditions, zero tool offset provided the optimum intermixing for this alloy combination.

3) AA6061 alloy is better suited to be positioned in the advancing side due to the enhanced material intermixing and better elongation.

4) EDX mapping confirms the distinct interface between both materials in the stir zone region.

\section{ACKNOWLEDGMENTS}

The authors would like to acknowledge National Science and Engineering Research Council (NSERC), Ministry of Higher Education Malaysia and Universiti Malaysia Pahang for research grants and funding.

\section{REFERENCES}

[1] Mishra RS, Mahoney MW. Friction Stir Welding and Processing. $1^{\text {st }}$ edition Materials Park, Ohio: ASM International; 2007.

[2] Guo S, Shah L, Ranjan R, Walbridge S, Gerlich A. Effect of quality control parameter variations on the fatigue performance of aluminum friction stir welded joints. International Journal of Fatigue. 2018;118:150-61.

[3] Sathari NAA, Shah LH, Razali AR. Investigation of single-pass/double-pass techniques on friction stir welding of aluminium. Journal of Mechanical Engineering and Sciences. 2014;7:1053-1061.

[4] Shah LH, Othman NH, Gerlich A. Review of research progress on aluminium-magnesium dissimilar friction stir welding. Science and Technology of Welding and Joining. 2018;23:256-70.

[5] Murr LE. A review of FSW research on dissimilar metal and alloy systems. Journal of Materials Engineering and Performance. 2010;19:1071-89.

[6] Hussein SA, Tahir ASM, Hadzley AB. Characteristics of aluminum-to-steel joint made by friction stir welding: A review. Materials Today Communications. 2015;5:32-49.

[7] Galvão I, Loureiro A, Rodrigues DM. Critical review on friction stir welding of aluminium to copper. Science and Technology of Welding and Joining. 2016;21:523-46.

[8] Mehta KP, Badheka VJ. A review on dissimilar friction stir welding of copper to aluminum: Process, properties, and variants. Materials and Manufacturing Processes. 2016;31:233-54. 
[9] DebRoy T, Bhadeshia HKDH. Friction stir welding of dissimilar alloys - a perspective. Science and Technology of Welding and Joining. 2010;15:266-70.

[10] Hasan MM, Ishak M, Rejab MRM. A simplified design of clamping system and fixtures for friction stir welding of aluminium alloys. Journal of Mechanical Engineering and Sciences. 2015;9:1628-39.

[11] Sabry I, El-Kassas AM. An appraisal of characteristic mechanical properties and microstructure of friction stir welding for Aluminium 6061 alloy - Silicon Carbide (SiCp) metal matrix composite. Journal of Mechanical Engineering and Sciences. 2019;13:5804-17.

[12] Wang X, Pan Y, Lados DA. Friction stir welding of dissimilar Al/Al and Al/Non-Al alloys: A review. Metallurgical and Materials Transaction B. 2018;49:2097-117.

[13] Kumar N, Yuan W, Mishra RS. Friction stir welding of dissimilar alloys and materials. Oxford: Butterworth-Heinemann; 2015.

[14] Ramachandran KK, Murugan N, Kumar SS. Effect of tool axis offset and geometry of tool pin profile on the characteristics of friction stir welded dissimilar joints of aluminum alloy AA5052 and HSLA steel. Materials Science and Engineering A. 2015;639:219-33.

[15] Firouzdor V, Kou S. Al-to-Mg friction stir welding : Effect of positions of $\mathrm{Al}$ and $\mathrm{Mg}$ with respect to the welding tool. Welding Journal. 2009;88:213-24.

[16] Liang Z, Chen K, Wang X, Yao J, Yang Q, Zhang L, et al. Effect of tool offset and tool rotational speed on enhancing mechanical property of Al/Mg dissimilar FSW joints. Metallurgical and Materials Transactions A. 2013;44:3721-31.

[17] Lv XQ, Wu CS, Padhy GK. Diminishing intermetallic compound layer in ultrasonic vibration enhanced friction stir welding of aluminum alloy to magnesium alloy. Materials Letters. 2017;203:81-4.

[18] Sahu PK, Pal S, Pal SK, Jain R. Influence of plate position, tool offset and tool rotational speed on mechanical properties and microstructures of dissimilar Al/Cu friction stir welding joints. Journal of Materials Processing Technology. 2016;235:55-67.

[19] Firouzdor V, Kou S. Al-to-Cu friction stir lap welding. Metallurgical and Materials Transactions A. 2012;43A:303-15.

[20] Xavier MF, Jayabalan V. Tool travel speed effects on the microstructure of friction stir welded aluminum - copper joints. Journal of Materials Processing Technology. 2015;217:105-13.

[21] Al-roubaiy AO, Nabat SM. Experimental and theoretical analysis of friction stir welding of $\mathrm{Al}-\mathrm{Cu}$ joints. International Journal of Advance Manufacturing Technology. 2014:1631-42.

[22] Wu LH, Nagatsuka K, Nakata K. Achieving superior mechanical properties in friction lap joints of copper to carbon-fiberreinforced plastic by tool offsetting. Journal of Materials Science and Technology. 2018;34:1628-37.

[23] Cavaliere P, Panella F. Effect of tool position on the fatigue properties of dissimilar 2024-7075 sheets joined by friction stir welding. Journal of Materials Processing Technology. 2008;206:249-55.

[24] Abhay PM, Madhusudhan SG. Dissimilar friction stir welds in AA2219-AA5083 aluminium alloys: Effect of process parameters on material inter-mixing, defect formation, and mechanical properties. Transactions of the Indian Institute of Metals. 2016;69:1397-415.

[25] Moradi MM, Aval HJ, Jamaati R. Microstructure and mechanical properties in nano and microscale SiC-included dissimilar friction stir welding of AA6061-AA2024. Materials Science and Technology. 2018;34:388-401.

[26] Zaman N, Noor A, Khan ZA, Shihab SK. Investigations on tunneling and kissing bond defects in FSW joints for dissimilar aluminum alloys. Journal of Alloys and Compounds. 2015;648:360-7.

[27] Guo J, Gougeon P, Chen X. Microstructure evolution and mechanical properties of dissimilar friction stir welded joints between AA1100-B 4 C MMC and AA6063 alloy. Materials Science and Engineering A. 2012;553:149-56.

[28] Cole EG, Fehrenbacher A, Duffie NA, Zinn MR. Weld temperature effects during friction stir welding of dissimilar aluminum alloys 6061-t6 and 7075-t6. International Journal of Advance Manufacturing Technology. 2014;71:643-52.

[29] Kumar K, Kailas S V. On the role of axial load and the effect of interface position on the tensile strength of a friction stir welded aluminium alloy. Materials and Design. 2008;29:791-7.

[30] Miranda AC de O, Gerlich A, Walbridge S. Aluminum friction stir welds: Review of fatigue parameter data and probabilistic fracture mechanics analysis. Engineering Fracture Mechanics. 2015;147:243-60.

[31] Ranjan R, Carlos de Oliveira Miranda A, Hui Guo S, Walbridge S, Gerlich A. Fatigue analysis of friction stir welded butt joints under bending and tension load. Engineering Fracture Mechanics. 2018;206:34-45.

[32] ASTM. Standard test methods for tension testing of metallic materials. Annual Book of ASTM Standards, 2001.

[33] Malin V. Study of metallurgical phenomena in the HAZ of 6061-T6 aluminum welded joints. Welding Research Supplement. 1995:305-18.

[34] Mathers G. The welding of aluminium and its alloys. Cambridge, England: Woodhead Publishing Limited; 2002.

[35] Liu H, Fujii H, Nogi K. Tensile properties and fracture locations of friction-stir welded joints of 6061-T6 aluminum alloy Tensile properties and fracture locations of friction-stir welded joints of 6061-T6 aluminum alloy. Journal of Materials Science Letters. 2003;22:1061-3.

[36] Ahmad Shah LH, Sonbolestan S, Midawi RH, Walbridge S, Gerlich A. Dissimilar friction stir welding of thick plate AA5052AA6061 aluminum alloys: effects of material positioning and tool eccentricity. International Journal of Advance Manufacturing Technology. 2019;105:889-904.

[37] Nunes AC. The evolution of friction stir welding theory at Marshall Space Flight Center. 9th Internationl Friction Stir Welding Symposium, Huntsville, Alabama: 2012, 1-19. 
[38] Wang B, Lei BB, Zhu JX, Feng Q, Wang L, Wu D. EBSD study on microstructure and texture of friction stir welded AA5052$\mathrm{O}$ and AA6061-T6 dissimilar joint. Materials and Design. 2015;87:593-9.

[39] Amancio-Filho ST, Sheikhi S, dos Santos JF, Bolfarini C. Preliminary study on the microstructure and mechanical properties of dissimilar friction stir welds in aircraft aluminium alloys 2024-T351 and 6056-T4. Journal of Materials Processing Technology. 2008;206:132-42.

[40] Ilangovan M, Rajendra Boopathy S, Balasubramanian V. Effect of tool pin profile on microstructure and tensile properties of friction stir welded dissimilar AA 6061-AA 5086 aluminium alloy joints. Defence Technology. 2015;11:174-84.

[41] Zhang P, Li SX, Zhang ZF. General relationship between strength and hardness. Materials Science and Engineering A. 2011;529:62-73.

[42] Kaufman JG. Properties of aluminum alloys: Tensile, creep and fatigue data at high and low temperatures. Ohio, USA: ASM International; 1999.

[43] Reynolds AP. Flow visualization and simulation in FSW. Scripta Materialia. 2008;58:338-42. 